\title{
Assessment of Magnitude and Factors Contributing to Obstructed Labor among Mothers Delivered in Mizan-Tepi University Teaching Hospital, Bench-Maji Zone, SNNPR, Ethiopia 2017
}

\author{
Sisay $\mathbf{S}^{1 *}$, Endris $\mathbf{M}^{2}$, Genet $\mathbf{Y}^{2}$, and Mohammed $\mathbf{M}^{2}$ \\ ${ }^{1}$ Department of nursing, Lecturer at Mizan Tepi University, college of health science, Ethiopia \\ ${ }^{2}$ Department of nursing, Mizan-Tepi University, Ethiopia
}

Submission: October 2, 2017; Published: October 20, 2017

*Corresponding author: Sisay Shewasinad, Lecturer at Mizan Tepi University, college of health science, department of nursing, Tel: +251948591580; Email: sisyehu@gmail.com

\begin{abstract}
Background: Obstructed labor is still major causes of maternal morbidity and mortality and adverse out comes for new born in low income countries. It is one of the common preventable causes of maternal and prenatal morbidity and mortality in developing countries. Africa has the highest maternal mortality in the world estimated at an average of about 1000 deaths per 100,000 live births.
\end{abstract}

Objective: the objectives of the study were to assess magnitude and factors contributing to obstructed labor among women delivered in Mizan-Tepi University Teaching Hospital.

Method: health facility based cross-sectional study design was carryout on mothers admitted to Obstetric ward from April 28/04/2017 to May 05/05/2017G.C. The study participants were selected using systematic random sampling techniques from records of all mothers delivered in the last one year. Data was collected using checklist by principal investigator of fourth year regular nursing students. Data was entered and analyzed by computer program in SPSS soft ware then tested by logistic regression to identify factors contributing to obstructed labor. Finally the result presented by using chart and table.

Result: in this study, the magnitude of obstructed labor is 51(15.6\%) from 327 participants. From the total participants, 185 (56.6\%) mothers in the age range of 20-29 years, 321 (98.2\%) are married, 198(60.5\%) are multi Para, $290(88.7 \%)$ of the study participants had ANC visits during their pregnancy and most of the cases $200(61.2 \%)$ has no referral from health center. Majority of the cases $313(95.7 \%)$ had no maternal complication of and $42(82.2 \%)$ infant delivered from obstructed mothers who did not develop complication.

Conclusion \& Recommendation: There is less magnitude of obstructed labor in MTU teaching hospitals due to larger baby weight, did not ANC visit and delay referred from health center. Prevent and managing of the cause of obstructed labor is one of the most important ways of reduction of maternal and prenatal mortality, and morbidity. In order to decrease high magnitude of obstructed labor; Lessen delayed arrival to hospital and Proper ANC follow-up by health workers and responsible bodies need to exert efforts to improve functioning of health centers and the referral systems.

\section{Introduction}

\section{Background}

Obstructed labor is failure of descent the fetal presenting part in despite of adequate uterine contraction [1]. It is a major cause of maternal morbidity and mortality in low income countries and accounts for approximately $8 \%$ of maternal death globally [2]. It is an important cause of maternal death in communities in which childhood under nutrition and early marriage is common. It also causes significant maternal morbidity mainly due to obstetric fistulae, skeletal and neurological complications and total death from asphyxia is common [3]. This is most likely an under estimated as the majority of maternal death due to obstructed labor as a primary causes of death are rarely documented; but instead document the terminal causes of death, hence are classified as sepsis, ruptured uterus or hemorrhage rather than the underlying causes [4]. Laboring mother presented with 
history of prolonged first stage of labor, early rupture of fetal membrane, and if labor delay with obstruction they present with secondary signs and complications. Such as, derangement of vital sign (e.g. low blood pressure), exhaustion, metabolic acidosis, genital sepsis, injury to the genital tract includes uterine rupture and PPH, bloody urine due to traumatized of the bladder, distended lower uterine segment with constriction ring (bandl's ring), edema of lower vagina and vulva (Kanula syndrome) due these Several procedures are done to relieve the obstruction in obstructed labor $[5,6]$.

\section{Statement of the problem}

Globally, each year over 210 million become pregnant of birth 20 million will experience pregnancy related illness and 500,000 will die as a result of the complication of pregnancy or child birth. Out of this about 4000 occurs in developing countries that account for $87 \%$ of the world's births. So in Africa this ratio is highest with value of $40 / 100.000$ live birth [7]. Similarly in Ethiopia an estimated maternal mortality of 32/1000 and pernatal mortality rate of 294/1000 were recorded [8]. The study in low income countries have reported the prevalence of obstructed labor to be between 2-8\% of all institutional deliveries [9]. Obstructed labor is a common obstetrical disorder to occur during child birth. It remains one of the important causes of maternal death and also short and long term disability. It has a particular impact in communities in which mechanic problem during labor are common and availability of functioning relevant health service is sparse. Obstructed labor comprises one of the five major causes of maternal mortality and morbidity in developing countries. The number of maternal deaths as a result of obstructed labor or rupture of uterus varies between $4 \%$ and $70 \%$ of all maternal death. Studies in Africa have reported high prevalence of obstructed labor during delivery. These are common among teenagers, early marriage, short stature women, primigravida, and multiple pregnancy including malnourished mothers [10].

Based on the retrospective survey, maternal deaths in a region of Uganda using the sisterhood method found $26 \%$ of 324 deaths to be attributable to obstructed labor. The risk of maternal death from obstructed labor is greatest in developing countries with poorly resourced health service. The risk factors for occurrence of obstructed labor are teenagers, early marriage, short stature women, primigravida and multipregnancy [11]. A similar proportion (19\% of 350 deaths) was identified in a prospective study using verbal autopsies, in Guinea Bissau [12]. Complication observed in women with obstructed labor at studied areas were puerperal sepsis in $57 \%$ of cases in Nigeria to $12.5 \%$ in India and extension at time of surgery in $14 \%$ of cases in India, maternal mortality from obstructed labor ranges from $32 / 1000$ in Nigeria to $11 / 1000$ in India [7,9]. The study done Addis Ababa University in Ethiopia by 2016G.C, the prevalence of obstructed labor is $34.30 \%$ of the total delivered women [13]. Other study in Adam Hospital, the magnitude of obstructed labor is 37 [9.6\%] from 384 participants included in the study which 34 [91.9\%] ware referred from nearby health center [14]. WHO has intensified its efforts to improve maternal health care focusing specifically on the reduction of maternal healthcare focusing specifically on the reduction of maternal mortality by strengthen the system of Primary health center care through formally trained health care providers and informal sector, particularly, the TTBA [10].

Demographic factors that contribute to the development of obstructed labor. These may include early pregnancy, before the age of 18 years early marriage, primigravida, failure to attend antenatal care, failure to monitor labor with partograph and distance from the hospital is the key elements which potentially place the pregnant mother to acquire obstructed labor [15]. In case of our study area, there is no data even though the problem is believed to be common. Therefore, this study was conducted in an attempt to asses' magnitude and factor contributing to obstructed labor among mothers delivered in Mizan-Tepi University Teaching hospital.

\section{Significance of the study}

This study was planning to assess magnitude and factors contributing to obstructed labor in Mizan-Tepi University teaching hospital. So there is no adequate information (data) on the magnitude of obstructed labor in Mizan-Tepi University teaching hospital as well as at the national level despite the fact that the problem is very common[16].

o The findings help the nursing profession and other health workers to know the magnitude of the problem in the study area.

o The study helps paramount importance to fill the gap regarding to the inadequacy of information about the problem.

o The findings of this study serve as base line for further study or serve as secondary data for other studies.

o The study helps to strength the information on obstructed labor in the developing countries.

\section{Objectives}

\section{General Objectives}

o To assess magnitude and factors contributing to obstructed labor among mothers delivered in MTUTH, BENCH MAJI ZONE, and SNNPR, ETHIOPIA 2016 G.C.

\section{Specific objectives}

o To determine magnitude of obstructed labor among mothers delivered in MTUTH, Bench-Maji zone, SNNPR, ETHIOPIA, 2016 GC.

o To identify factors contributing to obstructed labor among mothers delivered in MTU teaching hospital, BenchMaji Zone and SNNPR, ETHIOPIA, 2016 GC. 


\section{Methodology}

\section{Study area}

The study was conducted in MTU Teaching hospital is located in SNNPR, of ETHIOPIA, Bench- Maji zone, Mizan-Aman town $565 \mathrm{~km}$ from Addis Ababa and $835 \mathrm{~km}$ from regional town, Hawassa. The hospital has 4 wards (medical, pediatric, surgical, gynecology and obstetrics) and 1 emergency, 3 OPDs, MCH, ART, Ophthalmology, Dentistry departments. It has 1 gynecologist 0obstetricians, 1 surgeon, 22 GP, 11 Bsc nurses, 92 Clinical nurses, 14 clinical Midwives, 5Bsc midwives, 8 runners and 55 other staff workers. The hospital is providing services to south west Ethiopia population for around 8, 50538peoples from those female439345and 421193 male. In the year of 2016G.C 2068 mothers was delivered in MTU teaching hospital [17].

\section{Study period}

The data was collected from April 28/04/2017 to May 05/05/2017G.C

\section{Study design}

Health facility based cross-sectional study was used to assess magnitude and factors contributing to obstructed labor in MTU teaching hospital.

\section{Population}

Source populations: The source population records of all pregnant mothers gave birth in Mizan-Tepi University Teaching hospital in 2016GC.

Study population: The study population was sampled records of pregnant mothers gave birth in Mizan-Tepi University Teaching hospital in the least one year.

\section{Eligibility criteria}

Inclusion criteria: All records of women who are gave birth in MTU teaching hospital from January 01/01/2016 to December $31 / 2016$.

\section{Sample size determination and techniques}

Sample size determination: The sample size was determined by using single proportion formula with confidence interval of $95 \%$

$$
n=\frac{(Z / 2)^{2} P(1-P)}{D^{2}}
$$

Where,

$\mathrm{p}=$ total proportion $(34.3 \%)$ which is prevalence rate of OL in AAU, 2016. (13)

$$
Z_{\alpha / 2}=\text { confidence level at } 95 \%=1.96
$$
$5 \%$

$$
n=\frac{(1.96)^{2} 0.343(1-0.343)}{(0.05)^{2}}=346.28 \sim 347
$$

Since the population is relatively small (less than 10,000) we should adjust the sample size by using correction formula as follows.

$$
n=\frac{n_{0}}{1+\frac{n_{0}}{N}} n=\frac{347}{1+\frac{347}{2068}}=296.582 \sim 297
$$

Where $n=$ new sample size

$n_{0}=$ Initial sample size

$\mathrm{N}=$ total population $=2068$

By adding 10\% non response rate, sample size was 327

\section{Sampling techniques}

Systematic sampling technique was used to select 327 records. Sampling frame was prepared by using those mothers' card numbers from January01/01/2016 to December 31/ 2016. The $k$ interval was calculated by using following formula: $K=N / n$

o $\quad \mathrm{N}=$ number of mothers delivered in the last year.

o n=sample size. After $K^{\text {th }}$ interval computed, lottery method was used which was 4to identify starting point of sampled cards. Hence, K=2068/327=6

\section{Study variables}

\section{Dependent Variables}

o Obstructed labor

\section{Independent Variable}

i. Demographic factors like

$$
\begin{aligned}
& \text { o Age } \\
& \text { o Marital status }
\end{aligned}
$$
ii. Parity
iii. Antenatal care visit
iv. Referrer to hospital
v. Gestational diabetes mellitus
vi. Birth weight of the baby

\section{Operational definitions}

Obstructed labor: designated the phenomenon that despite adequate uterine contraction the delivery of the baby couldn't be accomplished timely in a normal, natural fashion but active intervention by health professionals will needed [18].

Parity: women who has previous viable infant.

Prim Para: A women who has giving birth for the first time.

Multi Para: A women who has two up to four children. 


\section{Global Journal of Reproductive Medicine}

Grand multi Para: When the number of previous similar deliveries was at least five.

Antenatal follow up: When the mother who has one or more visit at any health institution during her recent pregnancy and document in her cards.

Birth weight of the baby: When the weight of baby at birth is $400 \mathrm{gm}$ and above Macrodome, 2500gm-399gm normal weight1500gm-2499gm low birth weight,1000gm -1499gm very low birth weight and less $1000 \mathrm{gm}$ extremely low birth weight.

\section{Data collection procedure and Instrument}

The data was collected by using checklist from records carefully. So modified checklist was prepared as data collection tool. Data was collected by principal investigators of fourth year nursing students.

\section{Data quality control}

The data collection error and completeness was checked daily. Based on daily identified gap correction was done.

\section{Data analysis and presentation}

The data was entry in SPSS software. Data was analyzed using logistic regression. And identify factors contributing to obstructed labor. Finally the result was presented by using chart and table. $P$ value to identify significant variables was 0.2

\section{Ethical consideration}

To collect data permission letter was obtained from College of Health science for the cooperation of MTUTH. Also the permission is obtained from MTUH Metron to review patient medical record. The confidentiality and accountability for the secrets of the patient was secured throughout the study and information regarding the identification of the patient was recorded anonymously.

\section{Dissemination of the result}

The finding of the study was disseminating to Mizzen-Tepi University Collage of health science department of nursing. The copy of the final result was given to MTU teaching hospital

\section{Result}

\section{Socio demographic Characteristic}

In this study out samples, 327 were included providing response rate of $100 \% .185$ (56.6\%) mothers in the age range of 20-29 years. $93(28.4 \%)$ mothers in the age range of less than 19years. 321(98.2\%) of the participants are married and $198(60.5 \%)$ of the participants are multi Para. From 51(15.6\%) obstructed mothers $6(11.8 \%)$ mothers in the age range of $20-29$ years. $43(94.3 \%)$ mothers in the age range of less than 19years. $2(3.9 \%)$ mothers in the age range of 30-34years and mothers in the age range of greater than 35years was not encounter obstructed labor (Table 1) [19,20].

Table 1: Socio Demographic characteristics and parity of women who gave birth in MTU teaching hospitals, Bench-Maji zone, SNNPR, Ethiopian 2016.

\begin{tabular}{|c|c|c|c|c|c|c|c|}
\hline \multirow{3}{*}{ Variable } & \multirow{3}{*}{ Category } & \multirow{3}{*}{ Frequency } & \multirow{3}{*}{$(\%)$} & \multicolumn{4}{|c|}{ OL } \\
\hline & & & & \multicolumn{2}{|c|}{ Yes } & \multicolumn{2}{|c|}{ No } \\
\hline & & & & Frequency & $\%$ & Frequency & $\%$ \\
\hline \multirow{5}{*}{ AGE } & $=<19$ & 93 & 28.4 & 43 & 94.1 & 50 & 18.1 \\
\hline & $20-29$ & 185 & 56.6 & 6 & 11.8 & 179 & 64.9 \\
\hline & $30-34$ & 37 & 11.3 & 2 & 3.9 & 35 & 12.7 \\
\hline & $=>35$ & 12 & 3.7 & 0 & 0 & 12 & 4.3 \\
\hline & Total & 327 & 100 & 51 & 100 & 276 & 100 \\
\hline \multirow{4}{*}{ Marital status } & Single & 3 & 0.9 & 0 & 0 & 3 & 1.1 \\
\hline & Divorced & 3 & 0.9 & 1 & 2 & 2 & 0.7 \\
\hline & Married & 321 & 98.2 & 50 & 98 & 271 & 98.2 \\
\hline & Total & 327 & 100 & 51 & 100 & 276 & 100 \\
\hline \multirow{4}{*}{ Parity } & 1 & 98 & 30 & 24 & 47 & 74 & 27 \\
\hline & 4-Feb & 198 & 60.5 & 26 & 51 & 172 & 62 \\
\hline & $\geq 5$ & 31 & 9.5 & 1 & 2 & 30 & 11 \\
\hline & Total & 327 & 100 & 51 & 100 & 276 & 100 \\
\hline
\end{tabular}

\section{Obstetric characteristics}

In this study, 290 (88.7\%) of the study participants had ANC visits during their pregnancy while the rest 37 (11.3\%) had not visit. Out of $290(78 \%)$ participants $87(26.6 \%)$ had one visit, 65 (19.9\%) had two visit, 39(11.9\%) had three visit and the rest
99 (30.3\%) had four visit. From 51(15.6\%)obstructed mothers $14(27.5 \%)$ mothers had not ANC visit,29(56.9\%) had one ANC visit,7(13.7\%) had two ANC visit,1(2\%) had three ANC visit but mothers whose had four ANC visit no encounter to obstructed labor. In our study, most of the cases $200(61.2 \%)$ has no referral 
form health center, $91(27.8 \%)$ referrer at stage one, $27(8.3 \%)$ referrer at stage two, 8 (2.4\%) referrer when labor already obstructed and $1(0.3 \%)$ during APH and most of the cases involved 325(99.4\%) was no gestational DM but only 2(0.6\%) gestational DM cases were referred from health institution [21].
From 51(15.6\%)obstructed mothers 2(3.9\%) mothers had referrer themselves but $49(96.1 \%)$ referrer by health center in which $36(70.6 \%)$ had referrer at stage one ,12(23.5\%) had referrer at stage two,1(2\%) referrer when labor already obstructed but mothers whose no encounter to obstructed labor was referrer early (Table 2).

Table 2: Distribution of ANC visit and Referrer to hospital in obstructed labor MTU teaching hospitals, Bench-Maji zone, SNNPR, Ethiopia, and 2016GC.

\begin{tabular}{|c|c|c|c|c|c|c|c|}
\hline \multirow{3}{*}{ Variables } & \multirow{3}{*}{ Category } & \multirow{3}{*}{ Frequency } & \multirow{3}{*}{ (\%) } & \multicolumn{4}{|c|}{ OL } \\
\hline & & & & \multicolumn{2}{|c|}{ Yes } & \multicolumn{2}{|c|}{ No } \\
\hline & & & & Frequency & $\%$ & Frequency & $\%$ \\
\hline \multirow{3}{*}{ ANC } & Yes & 290 & 88.7 & 37 & 72.5 & 253 & 91.7 \\
\hline & No & 37 & 11.3 & 14 & 27.5 & 23 & 8.3 \\
\hline & Total & 327 & 100 & 51 & 100 & 276 & 100 \\
\hline \multirow{3}{*}{$\begin{array}{l}\text { Referrer to } \\
\text { hospital }\end{array}$} & Yes & 127 & 38.8 & 49 & 96.1 & 78 & 28.3 \\
\hline & No & 200 & 61.2 & 2 & 3.9 & 198 & 71.7 \\
\hline & Total & & 100 & 51 & 100 & 276 & 100 \\
\hline
\end{tabular}

\section{Baby weight at birth}

In this study, the baby weight in grams during delivery, weight $\leq 1500$ grams was $3(9 \%)$, weight between 1500 2500 grams was $44(13.5 \%)$, 2500-4000grams was 262(80.1\%) and weight $\leq 4000$ grams was $18(5.5 \%)$. From $51(15.6 \%)$ encounter obstructed labor. From this $38(74.5 \%)$ between $2500-4000$ grams,11(21.7\%) greater than or equal to 4000 grams, 2(3.9\%) between1500-2500grams and less than 1500gramshad not encounter obstructed labor (Figure 1) [22].

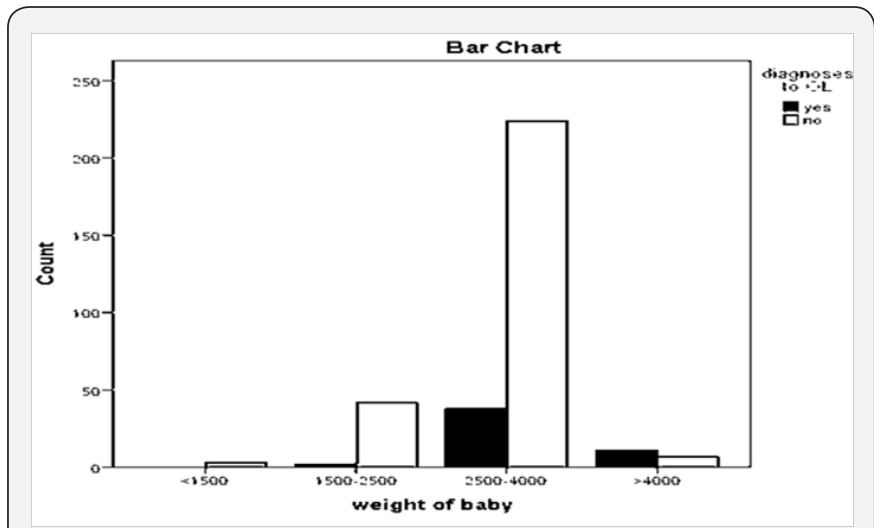

Figure 1: Distribution of baby weight in MTU teaching hospitals Bench-Maji zone, SNNPR, Ethiopia, 2016GC.

\section{Complications or outcome and management for the mother and neonate}

From 51(15.6\%) obstructed mothers 2(3.9\%) had been develop sepsis or wound infection and $1(2 \%)$ had been develop rapture uterus. But majority of obstructed mothers, that of $48(94.1 \%)$ had not been complication.

\section{Discussion}

In this study, the magnitude of obstructed labor is $51(15.6 \%)$ from 327 patricipants which greater than the study in AAU, the magnitude of obstructed labor is (34.3\%) from 387patricipants. This might be due to, hospital covering wide catchment area and some of the patients referred were already complicated. With regard to the age of study population, majority of study participants with obstructed labor cases recorded 43 (94.1\%) were age group $\leq 19$ years which is greater than the study in done AAU and the study done in JUSTH (2010), (26.5\%) were in the age group less or equal to 19 years and $61.5 \%$ ) in the age group of 20-29 years respectively [20]. The variation might be due to early marriage, early pregnancy and difference ways of age classification.

In our study, most of study participants accounts 321(98.2\%) were married which greater than the study done AAU, in which accounts 371 (96.4\%) were married and less than the study done in Adigrat, in which accounts $93.2 \%$ of the respondents were married [22]. Concerning the parity of study participants, majority of them were primiPara 26(51\%), followed by Para IIIV 24(47\%) Similarly the study done in JUSTH (2010) comprises $75(41.9 \%)$ were multi Para. The variation might be due to early marriage early pregnancy. In our study, 14 (27.5\%) did not have ANC follow up during their pregnancy. opposite to the study done in JUSTH (2010), 61.5\% didn't have ANC follow up during their pregnancy. Similarly in Pakistan, 69.5\% had not ANC follow up during pregnancy. The variation might be due to expansion of health center and health extension workers. Mothers who have fully or partially filled ANC visit significantly, 98.7 \%, less likely to encounter obstructed labor compared to those who have not $A N C$ visit $(\mathrm{P}=0.01, \mathrm{AOR}=0.013(1.378-15.254)$.

According to this study most of obstructed labor cases were referred from the health institution $49(96.1 \%)$. Similarly the study done in JUSTH (2010), most of the cases (81.0\%) have referred from health centers (20). This is almost similar with this study done in Mizan-Tepi university teaching hospital. 


\section{Global Journal of Reproductive Medicine}

In this study, from obstructed mothers $38(74.5 \%)$ of the new born had birth weight between 2500-4000grams followed by $11(21.7 \%)$ greater than or equal to 4000 grams But the study done in AAU, 58(38.2\%) of the new born had birth weight greater or equal to3500grams followed by $46(24.7 \%)$ of the new born had birth weight between 3000-34000grams. The variation might be due to difference ways of weight classification. Birth weight of baby between 2500 grams-4000gr significantly, $99.5 \%$, less likely to encounter obstructed labor compared to less than 1500 grams $(p=0.02, A O R=0.005(2.218-190.886)$. Finally in this study, age, marital status, parity, gestational diabetes and referrer to hospital were not associated with magnitude of obstructed labor. However, it is difficult to entirely dismiss the influence age, parity, gestational diabetes and referrer to hospital on obstructed labor judging by results of the logistic regression as it is contrary to many other studies which correlated obstructed labor and concluded age and parity were a strong predictor of obstructed labor $[13,21]$.This may be due to differences in methods used for the studies, distance of health facility.

Mothers who have fully or partially filled ANC visit significantly, $98.7 \%$, less likely to encounter obstructed labor compared to those who have not ANC visit. So there is association between mothers with ANC follow-up with obstructed labor. But other study in AAU, ANC visits had not association. In between 2500-4000 grams of baby weight had association with obstructed labor. But study done in AAU had no association regarding baby weight.

\section{Limitation}

Since the study was conducted by reviewing patient record, which is secondary data the whole information may not recorded properly this may lead to under estimation of the true magnitude of the problem. In addition to this our hospital base study may not represent the actual magnitude in the community because, only limited number of pregnant women deliver in the hospital and many rural communities have limited access to health care.

\section{Conclusion and Recommendation \\ Conclusion}

There is less magnitude of obstructed labor in MTU teaching hospitals due to ANC visit and good referred from health center. Prevent and managing of the cause of obstructed is one of the most important ways of reduction of maternal and prenatal mortality, and morbidity. In addition, early referral, and proper ANC followup with awareness on birth preparedness and complication and readiness and, delivery by skilled birth attendant minimizes the risk of maternal and prenatal complication.

\section{Recommendation}

In order to decrease magnitude of obstructed labor; lessen delayed arrival to hospital and Proper ANC follow-up by health workers and responsible bodies need to exert efforts to improve functioning of health centers and the referral systems. Give education for the community about the impacts of early marriage in obstructed labor.

\section{References}

1. Health LG (2014) United Nations agencies report steady progress in saving mothers' lives, New Tork, USA.

2. Bank W (2015) The world banks reproductive health action plan 20102015.

3. Arrow S, Hamlin C, Wall L (1996) obstructed labour injury complex obstetric fistula, Obstet Gynecol suru 51(9): 568-574.

4. Ali AA, Adam L (2010) Maternal and prenatal outcome of obstructed labor in kassala hospital, Sudan's. J Obstetric gynecol 30(4): 376-377.

5. Gaym A (2002) Obstructed labour at a district hospital. Ethiopia med J 40(1): 11-18.

6. Ozumba BC, Uchagbu $\mathrm{H}$ (2003) Incidence and management of obstructed labour in eastern Nigeria A. Aust NzJ obstect Gynecol 31(3): 213-216.

7. Chabral S, Gandhi D, Jailual M (2008) Obstructed labour a preventable entity. J obstet gynacol 20(2): 151-152.

8. Gessessew A, Mesfin M (2007) Obstructed labor in Adigrat zonal hospital, Tigray regional Ethiopia, ethno J. health Dev 17(3): 175-180.

9. Nwogu- kojo EE, Nwezes so, Ezegulu HU (2008) Obstructed labor in Enugu, Nigeria. J obstet gynecol 28(6): 596-599.

10. WHO, Geneva world health organization: 2000, the world health report: 2005: make every mother and child count available

11. Mccarthy M (2005) In what going on at world health organization. Lancet 360: 1108-1110.

12. WHO the world health report 2005: make every mothers and child count, Geneva, world health organization: 2005: 230

13. Tezita T (2016) Obstructed labor in west Harerghe zone, Oromo Region, Ethiopia, AAU, June 2016.

14. Asnakech T, Tilaye W (2016) Obstructed Laborin Adama Hospital medical College, Oromia Central Ethiopia Journal of Gynecol and Obstetrics 4(3): 12-16.

15. Shaikh S, Shaikh A, Shaikh S, Isran B (2013) Frequency of Obstructed Labor in Teenage Pregnancy. Nepal J Obstet and Gynaecol 7(1): 37-40.

16. Chabral S, Gandhi D, Jailual M (2008) Obstructed labour a preventable entity. J obstet gynacol 20(2): 151-152.

17. Adanu RM, Abed SA (2003) Ruptured uterus a several year review from Accro-Ghana. J obstetric Gynecol 25(3): 225-230.

18. Fawole A (2011) Obstructed Labour in Ilorin, Nigeria-A One Year Prospective. Niger Med Pract 38: 1-3.

19. Kabakyenga JK, Östergren PO, Turyakira E, Mukasa PK, Pettersson KO (2011) Individual and health facility factors and the risk for obstructed labour and its adverse outcomes in southwestern Uganda. BMC Pregnancy Childbirth 11: p. 73.

20. Fantu S, Segni H, Alemseged F (2010) Influences', caues and outcomes of obstructed labour in JUSH. Ethiopia 20(3): 145-151.

21. Kip JP (2013) The prevalence of obstructed labour among pregnant women at a selected hospital, west wollega, ethiopia.

22. Gessessew A, Mesfin M (2003) Obstructed labour in Adigrat Hospital, Tigray Region. Ethiop. J Health Dev 17(3): 175-180. 
This work is licensed under Creative Commons Attribution 4.0 Licens

DOI: 10.19080/GJORM.2017.02.555592
Your next submission with Juniper Publishers will reach you the below assets

- Quality Editorial service

- Swift Peer Review

- Reprints availability

- E-prints Service

- Manuscript Podcast for convenient understanding

- Global attainment for your research

- Manuscript accessibility in different formats

( Pdf, E-pub, Full Text, Audio)

- Unceasing customer service

Track the below URL for one-step submission https://juniperpublishers.com/online-submission.php 